\title{
Emerging Technology: What is it?
}

\author{
Mohanad Halaweh
}

\begin{abstract}
The term emerging technology (ET) has been frequently used by IT professionals and academics. However, little research has shed light on this term and specified its characteristics and what it means. Therefore, this paper aims to define and conceptualize the characteristics of ET. These characteristics are uncertainty, network effect, unseen social and ethical concerns, cost, limitation to particular countries, and a lack of investigation and research. Several examples of ETs are given to validate these characteristics.
\end{abstract}

Keywords: emerging technology; technology adoption; IT maturity; uncertainty. 


\section{Introduction}

The term emerging technology (ET) has been frequently used by IT professionals and academics. For example, NFC (near field communications), cloud computing, ambient intelligence, virtual reality, and social network websites are labeled as emerging technologies (ETs) (Stahl, 20I I; Özdenizci et al., 20 I0, Siemens \& Tittenberger, 2009). However, little research has shed light on this term and specified its characteristics and what it means. The question of when a technology can be labeled as an emerging technology and when it can be labeled as a traditional/well-established technology remains. One of the main challenges when investigating ETs is the fact that the term is in many cases not well defined and is often misunderstood (Gachago et al., 2013;Veletsianos, 2010). This paper aims to define and conceptualize the characteristics of ET.To limit the scope, this paper will consider ET within the information and communication technology (ICT) domain. This paper is organized as follows. Section 2 defines emerging technology. Section 3 demonstrates the characteristics of ET by providing several examples to validate these characteristics. Section 4 provides discussion, conclusions, and recommendations for future research.

\section{Definition of Emerging Technologies (ET)}

There is no widely agreed-upon definition of "emerging technologies." Very few articles provide a clear scope and complete definition for ET, and searching for an ET definition using a search engine does not return much information. Day and Schoemaker (2000) and Srinivasan (2008) state that ETs are science-based innovations with the potential to create a new industry or transform an existing one. For example, record label companies and the DVD market were destroyed because of the emerging Apple store and the iPod. The use of the word "science" means that ETs are produced from the collaboration of research and development, as most ETs begin as a conceptual research idea before they are created and developed. The Business Dictionary defines ET as "new technologies that are currently developing or will be developed over the next five to ten years, and which will substantially alter the business and social environment" (www. businessdictionary.com ). This definition considers new technology as ET, which is not entirely accurate. This is one of the main misconceptions about ET. Technology can still be considered emerging in one context even though it has been considered established in another. The context here is related to place, domain, or application. For example, Radio Frequency Identification (RFID) is not considered emerging in developed countries, whereas it is described as an ET in other poor and developing countries in the world where the Internet and communication technology infrastructures are still poor. Geographic information systems are considered established tools in the real estate and agriculture industries, but they are still considered to be emerging in the teaching of K-12 geography (Doering \& Veletsianos, 2007). The Web was invented in 1990-199| so it not labeled as an ET. However, various uses of the Web in different applications can make it an ET. This has been recently labeled Web 2.0 and Web 3.0, or the second and third generations of the Web. For example, Twitter, Facebook, and YouTube are ETs for journalists and the media. They have caused revolutions in Arabic countries, demonstrating how ET can change the social environment as defined by the Business Dictionary.

Miller et al. (2005) stated: A technology is still emerging if it is not yet a "must-have." For example, a few years ago email was an optional technology. In fact, it was limited in its effectiveness as a communication tool when only some people in an organization had regular access to it. Today, it is a must-have, must-use technology for most people in most organizations. In this sense, a technology can be a standard expectation in the commercial or business world, while still being considered as "emerging" in the education sector. (p. 6)

This definition focuses on the usage of technology and the extent to which it is widespread in a particular context or domain. This also conforms to Daniel et al.'s (1998) view of ET as something that is commercially available but not common or something that could become commercially available within the next five years. This definition implies that technology does not need to be new to be considered an ET (Vine, 2002). Rather, technology is considered emerging if it is not widely available in the market and used by people. In the project titled "Ethical Issues of Emerging ICT Applications (ETICA)," funded by the European Commission, Stahl (20II) studied the ethical implications associated with emerging technologies. He defined ET as technologies that have the potential to gain social relevance within the next 10 to 15 years. He adds that this means they are not only currently at an early stage in their development process, but they have already moved beyond the purely conceptual stage. The Business Dictionary definition of ET specifies that technology is considered emerging for the first 5 to 10 years of its lifecycle, whereas Stahl (20II) states that technology is emerging for the first 10 to 15 years. This is another misconception about specifying a range of time in a technology's lifecycle to determine if a technology is emerging. For example, virtual worlds were described as an ET in the mid-1990s (Dede, 1996). However, virtual worlds are still described as an ET. For example, Second Life (a 3D virtual world) is labeled as an ET (Barnetta, 2009). This means that the life of a technology can exceed 15 years and the technology can still be considered emerging, as is Second Life, which is still in its early revolution and is being discovered by many business models. 
To sum up, ETs are not necessarily new. Technology is labeled as emerging in a particular context (domain, place, or application) but can be established elsewhere. Technology is also considered emerging when it is not widespread in a particular context. ET has no limited or fixed life. Technology is defined as emerging when it causes a radical change to business, industry, or society.

\section{Characteristics of Emerging Technology}

The following sections describe the characteristics of ETs, which are also summarized in Table I.

\section{Uncertainty is high}

Srinivasan (2008) pointed out that the only certainty with ETs is the high degree of uncertainty associated with them. The returned value/return on investment from an ET and the penetration rate at the early stage of the ET's lifecycle are unclear. ET transforms businesses and industries and sometimes destroys others. ET leads to radical change, and some firms prefer to wait for other leader firms to take the risk. Uncertainty is a core feature of ET. This is due to the nature of ET, whose future is unknown or unpredictable; what the ET holds for the future is unclear (Stahl, 20I I). The uncertainty associated with a new technology takes several forms, such as uncertainty over prices or lack of knowledge about costs (Rosenberg, 1996). Meyer (2008) pointed out that technological uncertainty is represented by a lack of common knowledge and agreement about what production technology will be relevant in the future. Furthermore, the lack of certainty and limited knowledge about technology standards and specifications, business models, and social implications make it impossible to describe the existing state or future outcome of ETs (Stanoevska-Slabeva, 2003). The uncertainty of future applications due to the lack of clearly defined business models in the early stages of technology lifecycles has led to skepticism (Schnicke, 2002). For example, Wang and Cheong (2005) stated that since mobile commerce was still in its infancy in 2005 , there would be a lot of uncertainty about its future. This uncertainty caused the emerging mobile commerce market to be complicated. Åkesson (2007) also notes that one of these uncertainties is related to the relative novelty of technology (i.e., m-commerce). This makes it very difficult to measure how people act in response to new services (Åkesson, 2007). Thus, uncertainty here is related to different variables whose values are unknown, unpredictable, or unstable such as cost, penetration rate, technology standards and specification, and user acceptance and reactions.

It is clear that one source of uncertainty is a lack of standards and specifications for an ET. For example, NFC is considered an ET (Özdenizci et al., 2010). NFC is a wireless communication technology that enables the transfer of data over distances of up to 10 centimeters. This technology is used for mobile payments in the retail industry. NFC specifications are set by stockholders and players, which include MasterCard, Microsoft, Nokia, Samsung Electronics, Sony, Visa, Sony Ericsson Mobile Communications $A B$, Research In Motion, and others (NFC Forum, 2012). The NFC Forum was formed in 2004 to advance the use of NFC technology by developing specifications, ensuring interoperability among devices and services, and educating the market about NFC technology. However, regarding specifications and standards, the NFC Forum website mentions that:

Work on more specifications is well underway. As a notfor-profit organization with many members contributing different input and views, it takes time for the NFC Forum to reach agreement and progress toward our goals. Other specifications in progress include Simple NDEF Exchange Protocol (SNEP), the NFC Controller Interface $(\mathrm{NCl})$, and the RF Analogue Protocol. (http://www.nfc-research.at/)

Consequently, some specifications and standards were created in 20I I-20I2 to ensure that mobile-enabled NFC meets global interoperability, with more in progress. The lack of uniform standards has resulted in a lack of mobile-enabled NFC products, leading to a low penetration rate. However, this uncertainty gradually vanishes with time. If one refers back to 2004, much progress has been made. The timing factor is important. Since most ETs begin as a conceptual idea, some people or organizations wait until an ET matures and has specifications and standards. They may also wait until it is provided by many manufacturers so its price decreases due to strong competition. Before an ET is produced by many manufacturers, its standards and specifications need to mature. Gunasekaran and Harmantzis (2007) also pointed out that the standardization and interoperability between different vendor products have lowered $\mathrm{Wi}$-Fi prices and facilitated its rapid penetration from a niche market into the worldwide mass market. The maturity of a technology is important because in the early stages of an ET's lifecycle, the initial adoption rate is very low because it is not stable. ET maturity leads to uniform standards for all developers, manufacturers, service providers, and end users. IT maturity has a positive impact on the adoption of IT investment evaluation approaches (Lin et al., 2007). This means that a decision to invest in a new ET depends on its level of maturity.

\section{Network effects}

The value and power of a network increases by increasing the number of people who use or are connected with that network. This law was formulated by Ethernet inventor Bob Metcalfe in the 1970s (Metcalfe, 1995). For example, the value of a fax machine is zero if no else has a fax ma- 
chine. As the number of people (n) who own fax machines increases, the value of the fax machine to each user in the network increases. If only one user has adopted the ET, then its value in this context is meaningless. If two people adopt it, then the value is appreciated, and the value further increases if more do so, which increases adoption. For example, the number of users who have adopted Facebook is increasing due to its value, which increases by increasing the number of adopters. The number of users of an ET in a particular context begins low and then gradually increases. This is also correlated with time. As long as time passes, the number of users will increase and the value of the ET will increase. Another example of ET is using NFC technology enabled in smartphones for mobile payments. The first trials for NFC technology started in 2006-2007 (http://www.nfc-research. at/). The first NFC-enabled mobile phone was developed by Nokia in 2006 (the Nokia 6131). Juniper Research forecasts that there will be a rapid adoption of NFC and that one in five users worldwide will have an NFC-enabled phone by 2014 (http://www.juniperresearch.com/ ). However, it is not worth having mobile-enabled NFC if no payment services using this technology are provided by merchants. If the majority of shops accept payment through NFC, the value of this technology will increase as will the number of adopters.

\section{Unseen social and ethical implications}

One feature that uniquely differentiates ET from other forms of technology is the fact that its social and ethical impact is not seen or known when the technology is eventually brought to the market or to a particular context. Usually, the added values and benefits are obvious. However, ethical concerns may arise depending on its application. If an ET is put into a new context, a new concern emerges. The impact of an ET changes as its application changes. For example, Radio Frequency Identification (RFID) was initially used for inventory management. When it was used for tracking criminals, it raised ethical concerns and debates about the tradeoff of peoples' privacy rights and countries' national security. Sandler (2009) indicated that some people have misconceptions about ethics and emerging technology. One of these is the belief that "it is too soon to tell what the social and ethical issues are" (Sandler, 2009, p. 6). This is due to the narrow focus on the technology's benefits and capabilities and the neglect of broader contextual factors. In addition, Lucas (20II) pointed out that designers are not always aware that they are making ethical decisions when they develop or design new technology. Hence, these ethical problems are often discovered after the technology is placed in a particular context (e.g., place, domain, and application) and use. Therefore, when a new ET is created or used in a particular context, its emerging ethical concerns should be highlighted in the early stages of its lifecycle in order to use this technology in a way that does not harm societal and human values such as life, health, justice, freedom, happiness, privacy, and security. Although NFC technology is a relatively new emerging technology and is still not widely used, Halaweh (20I2) addressed some of the social and ethical issues that could be raised, such as inequality among customers and privacy violations. He noted that this technology could increase inequality between people because it enables individuals who have Blackberry mobile phones, for example, to enjoy rapid payment services at checkout points, whereas others who do not have a smartphone will have to wait longer to pay by cash or with a credit card. An additional ethical concern is that banks will know more about customers, as they will use NFC-enabled mobile phones to pay for every purchase. Banks can collect data about their customers and analyze it to identify customers' purchase patterns and behaviors. In addition, technology might replace the traditional method of payment like carrying cash in one's pocket. Hence, it increases people's reliance on technology and the ubiquity of mobile phones. Although some of these concerns are not seen now, their impact might be discovered later when the technology becomes widely accepted and used by people and merchants. However, addressing such concerns in early stages could help in setting proactive actions to deal with them.

\section{Costs}

The term "emerging" is often taken to mean emerging from research and development (Vine, 2002). Cozzens et al. (2008) pointed out that because ETs are research-based, they are more likely to be sold at high prices as firms try to recover research and development costs. Cozzens et al. (2009) stated that the high costs increases the potential of ETs to increase inequalities in access among users. Although the point discussed here is related to costs, this also affirms the previous notion that ETs raise ethical and social concerns (i.e., inequality in accessing technology). On the other hand, Srinivasan (2008) pointed out that the costs during the early stages of the technology evolution process are low because the new technology is "buggy" with low performance and as the technology develops, its "bugginess" is eliminated. Thus, its performance and price ratio increase, and the potential benefits from the ET move from a narrow market to a larger mass market. New ET is always very expensive in the beginning because the initial production volumes are very low. These volumes are low because very few manufacturers produce it; there is no certainty regarding adoption volumes. However, by the time the technology maturity increases, the number of manufacturers increase and the competition increases between them. Consequently, the cost drops in correlation with time. Hence, over time, the cost decreases and the spread increases. For example, the cost of an RFID tag started at $\$ 1.20$ in 2005 but dropped to .05 cents by 2012. (http://moscatiello.net/) (http://www. rfidjournal.com/). 
Another example is that the price of NFC-enabled smartphones started at approximately $\$ 700$, which is relatively high even in high-income countries. Users who would like to benefit from NFC technology have to purchase a smartphone that has this technology. The NFC chip is not sold separately for users to add to their phones. Therefore, they have to exchange their old mobile phones for one that is NFC enabled; replacing old technology with ET is very high. The NFC microchip price might be cheap but the mobile phone that contains the chip is expensive; yet, this chip is available in a limited number of mobile phone brands. Therefore, its penetration and usage is delayed. If the chip is integrated into most inexpensive or affordable mobile phones, customers will accept it and merchants will offer mobile payments through this ET.

\section{ETs are limited to particular countries}

Technology-creating countries will always appear to be leaders who are starting revolutions, and technology-using countries will always appear to be attempting to catch up (Cozzens et al., 2009). New ETs have been developed in North America, Europe, and North Asia and then diffused to other parts of the world, either when a multi-national firm decides to place a production facility there or when the technology becomes available for purchase. For exam- ple, the first trials of NFC use started in the United States, Canada, United Kingdom, and Japan between 2006 and 2008 (Chidembo, 2009). Other countries, such as the UAE, introduced NFC technology for payment services in 20II-20I2 (http://www.telecoms.com/ ). Of course, many countries are behind in terms of adoption and use of this technology. Industry-governmental coordination and support is important to the introduction and adoption of ET to a new context. Gunasekaran and Harmantzis (2007) pointed out that the penetration of wireless emerging technologies, such as WiMAX, requires national policymaker initiatives to develop suitable strategies that promote them, thereby maximizing the social and economic benefits to the country and its citizens. In their study of six innovations across 31 developed and developing countries, Talukdar et al. (200I) found that developing countries still demonstrated slower adoption rates than developed countries. Affluent countries compete for leadership in ET, and in the past, some less affluent countries found significant opportunities in the wide-open spaces of the technology emergence process (Cozzens, 2009). The availability of ET is an important condition for adoption. People in developing countries and less developed countries may hear about a new ET. However, because of economic conditions, they are unable to enjoy this technology even though they wish to have it. If it is available to them, they will adopt it.

\begin{tabular}{|l|l|}
\hline Characteristics & Description \\
\hline ET uncertainty & $\begin{array}{l}\text { The uncertainty associated with ET takes several forms with un- } \\
\text { known and unpredictable values and outcomes, such as standards } \\
\text { and specifications (maturity), business models, price, and adoption } \\
\text { rate uncertainties. } \\
\text { As time passes, the ET becomes more matured and diffused and } \\
\text { the number of adopters increases while costs drop. In contrast, } \\
\text { ethical and social concerns might increase as ET is used in new } \\
\text { applications. }\end{array}$ \\
\hline ET network effect & $\begin{array}{l}\text { The value of an ET increases by increasing the number of ET us- } \\
\text { ers. }\end{array}$ \\
\hline ET costs & $\begin{array}{l}\text { The cost of owning the ET is high, and the cost of substituting } \\
\text { traditional technology with the ET is high. }\end{array}$ \\
\hline Unobvious ET impact & $\begin{array}{l}\text { The social and ethical impacts associated with the use of ET are } \\
\text { unseen, unknown, or unexpected before its adoption/use or at an } \\
\text { early stage of the ET life cycle. }\end{array}$ \\
\hline $\begin{array}{l}\text { ET is limited to creator or } \\
\text { inventor country (availabil- } \\
\text { ity of ET) }\end{array}$ & $\begin{array}{l}\text { ET is usually available for use in a particular context or in the } \\
\text { country that creates or invents it. }\end{array}$ \\
\hline $\begin{array}{l}\text { ETs are not fully investigat- } \\
\text { ed and researched }\end{array}$ & $\begin{array}{l}\text { Most of the materials on ET are white papers and technical reports } \\
\text { produced by the manufacturers of the ET with little scientific/aca- } \\
\text { demic research. }\end{array}$ \\
\hline
\end{tabular}

Table I. Characteristics of ET

ISSN: 07I 8-2724. (http://www.jotmi.org) 


\section{ETs are not fully investigated and researched}

In addition, research on ET is still not fully saturated; few articles are published. Most of the materials on ET are white papers and technical reports produced by manufacturers and stakeholders who benefit from this technology. This point was also asserted by Veletsianos (2010) and Thomas et al. (2009). This makes firms, governments, and decision makers unable to make decisions about ET adoption, applications, usage, and social implications because the main audience for these materials is professional industry personnel, which usually focus on the technical side of the ET. Well-established research about an ET's specifications, features and capabilities, limitations, and social implications will increase its adoption. For example, Thomas et al. (2009) pointed out that little scientific research has been published on NFC due to its recent emergence. Özdenizci et al. (2010) also noted that the literature review on NFC does not include many articles published in journals. Okazaki (2005) also pointed out that in 2005, the empirical explorations of m-commerce had experienced only modest growth because of the considerable uncertainties involved in mobile research. Therefore, well-established research on ET increases its maturity, knowledge about it, and thus its adoption.

\section{Discussion and Conclusion}

This paper has elucidated the term "emerging technology" and its characteristics and highlighted some misconceptions about it. It is important to mention that the characteristics discussed in this paper are not necessarily present in all emerging technologies. For example, when a technology is labeled as emerging in one context (e.g., domain, place, application) but is considered traditional/established in another context, then the ET in this case is mature and stable. Hence, uncertainty is not a relevant characteristic in this case, at least with regard to the maturity of technology specifications and standards. Therefore, one can state that these characteristics are fully relevant when the technology is emerging and completely new.

The ET adoption rate increases over time; it starts with low availability (in markets, societies, and countries) and a low network effect. However, availability increases over time as the number of ET manufacturers and providers increase and spread across borders and developed industrial countries (for example, smartphones are produced by many manufacturers in Europe and Asia, resulting in increased market availability). However, ETs can be available but not adoptable or neither available nor adoptable because of economic conditions or exclusive restrictions of an ET to the manufacturer's country or inventors in a particular country. The ET network effect increases over time. For example, the network effect of Web 2.0 applications is increasing over time because of the increasing number of network users. ET also starts with low technology maturity with incomplete specifications and non-uniform standards. Additionally, few or unobservable ethical and social problems are present at the beginning of an ET. However, as time passes, the number of ethical and social concerns gradually increases. The reason is that when ET is used in different applications, new and unforeseen concerns arise. In contrast, as time passes, the cost of ET gradually drops and the level of uncertainty decreases. The literature review includes extensive research that has investigated users' and organizations' intentions to adopt and use new technologies in different contexts (e.g., e-commerce, m-commerce, e-banking, e-learning, and enterprise systems). Most technology adoption research is based on two main theories: Technology Acceptance Model (TAM) (Davis, 1989) and Innovation Diffusion Theory (IDT) (Rogers, 1995). They are used to predict and test the factors that influence the acceptance and adoption of technology. However, investigating the adoption of ET might require additional, unique, non-traditional factors (constructs) rather than those specified in TAM and IDT. Therefore, this poses a question: Are the factors that influence the adoption of traditional/established technology identical to or different from those that influence the adoption of ET? For example, traditional technology acceptance and adoption theories do not consider the special characteristics of ET, such as uncertainty, ET maturity, network effect, and cost. Therefore, integrating these characteristics with TAM and IDT will provide further insights into the adoption and acceptance of any new emerging technology. This could be an interesting area for future research. 


\section{References}

ÅKESSON, M., (2007). Value proposition in m-commerce: exploring service provider and user perceptions. Presented at LA Global Mobility Round Table, Los Angeles, May 3I-June 2.

BARNETTA, A. (2009). Fortune 500 companies in Second Life: Activities, their success measurement and the satisfaction level of their projects. Master Thesis, ETH Zurich.

CHIDEMBO, N. (2009). Exploring Consumer Adoption of NFC-Enabled Mobile Payments In South Africa. Master Thesis, University Of Pretoria.

COZZENS, S. (2009). E. Emerging Technologies and Inequalities: Beyond the Technological Transition. Presented at GLOBELICS 2009, 7th International Conference, 6-8 October, Dakar, Senegal.

DAY, G., Schoemaker, P. (2000). Wharton on managing emerging technologies. New York, NY: John Wiley and Sons, Inc.

DAVIS, F. D. (1989). Perceived usefulness, perceived ease of use, and user acceptance of information technology. MIS Quarterly, I3(3), 319-349.

DEDE, C. (1996). Emerging technologies and distributed learning. American Journal of Distance Education, 10(2), 4-36.

DOERING, A., Veletsianos, G. (2007). An investigation of the use of real-time, authentic geospatial data in the K-12 classroom, Journal of Geography, I06(6), 2 17-225.

GACHAGO, D., Ivala, E., Backhouse, J., Bosman, J.; Bozalek, V., Ng'ambi, D. (20I3). Towards a Shared Understanding of Emerging Technologies: Experiences in a Collaborative Research Project in South Africa. The African Journal of Information Systems: 5(3), 94- 105.

GUNASEKARAN, V., Harmantzis, F. C. (2007). Emerging wireless technologies for developing countries, Technology in Society, 29, 23-42.

HALAWEH, M. (20I2). Ethical Considerations Raised by Using Near Field Communication Technology for Mobile Payments. European. Mediterranean \& Middle Eastern Conference on Information Systems (EMCIS), Munich, Germany 7-8 June, 2012.

LIN, C., Huang,Y., Cheng, M. (2007). The Adoption of IS/IT Investment Evaluation and Benefits Realization Methodologies in Service Organizations: IT Maturity Paths and Framework. Contemporary Management Research, 3(2), 173-194.
LUCAS, I. (2012) "Phenomenological Approaches to Ethics and Information Technology", The Stanford Encyclopedia of Philosophy (Summer 20II Edition), Edward N. Zalta (ed.). http://plato.stanford.edu/archives/sum20I l/entries/ethics-itphenomenology/ [Accessed December 12, 20II]

MANN, D., Mendenhall, J. (1998). Technical Assessment of Residential and Small Commercial Emerging Technologies. San Francisco, CA: Pacific Gas \& Electric Company.

METCALFE, B. (1995). Metcalfe's Law: a network becomes more valuable as it reaches more users. Infoworld.

MILLER, J., Green, I., Putland, G. (2005). Emerging Technologies: A Framework for Thinking. Australian Capital Territory Department of Education and Training. http://www.det.act. gov.au/_data/assets/pdf_file/00 I0/74485/ACT_EmTech_ Report_vl_2.pdf [Accessed January 2I, 20I2]

OKAZAKI, S. (2005). New perspectives on m-commerce research, Journal of Electronic Commerce Research, 6 (3).

ÖZDENIZCI, B., M. Aydin, V. Coşkun, K. Ok (2010). NFC Research Framework: A Literature Review And Future Research Directions. Published in I4th IBIMA Conference, 2324 June 2010.

ROGERS, E.M. (1995). Diffusion of Innovations, (Fourth ed.). New York, NY:The Free Press.

ROSENBERG, N. (1996). Uncertainty and Technological Change. In Mosaic of Economic Growth, edited by Ralph Landau, Timothy Taylor, and Gavin Wright. Stanford University Press.

SANDLER, R. (2009). Nanotechnology:The Social and Ethical Issues, Woodrow Wilson International Center for Scholars. http://www.nanotechproject.org/process/assets/files/7060/ nano_pen 16_final.pdf [Accessed January 21, 2012]

SCHNICKE, S. (2002). The Problem of Personalization in Location Based Services. http://groups.haas.berkeley.edu/fcsuit/ Pdf-papers/Schnicke.pdf [Accessed September 15, 20I3]

SIEMENS, G., \& Tittenberger, P. (2009). Handbook of Emerging Technologies for Learning - Emerging Technologies forLearning. http://elearnspace.org/Articles/HETL.pdf [Accessed September 15, 2013]

SRINIVASAN, R. (2008). Sources, Characteristics and Effects of Emerging Technologies: Research Opportunities in Innovation. Industrial Marketing Management, 37, 633-640.

ISSN: 07I 8-2724. (http://www.jotmi.org) 
STAHL, B. C. (20I I). What does the Future Hold? A Critical View of Emerging Information and Communication Technologies and their Social Consequences. In M. Chiasson, $\mathrm{O}$. Henfridsson, H. Karsten, \& J. I. DeGross (Eds.), Researching the Future in Information Systems: IFIPWG 8.2 Working Conference, Future IS 20II, Turku, Finland, June 6-8, 20II, Proceedings (Ist ed., pp. 59-76). Heidelberg: Springe

STANOEVSKA-SLABEVA, K. (2003). Towards a Reference Model for M-Commerce Applications", In Proceedings of European Conference on Information Systems, 2002 http://aisel.aisnet.org/ecis2002/I59 [Accessed September 15, 20I3]

TALUKDAR, D., Suhir, K. (200I). Investigating New Product Diffusion across Products and Countries' SSRNWorking Paper Series. Oct $200 \mathrm{I}$.

THOMAS J. P., Andreas, S., Frédéric, T., Elgar, F. (2009). NFC Based Service Innovation in Retail: An Explorative Study, 17th European Conference on Information Systems, Verona, Italy, 8-10 June 2009.

VELETSIANOS, G. (2010). Emerging Technologies in Distance Education. Athabasca University Press. Edmonton : AU Presshttp://www.aupress.ca/books/ I 20177/ebook/99Z_ Veletsianos_2010Emerging_Technologies_in_Distance_Education.pdf [Accessed May 15, 20I3]

VINE, E. (2002). Promoting emerging energy-efficiency technologies, and practices by utilities in a restructured energy industry: A report from California. Energy, 27 (4), 317-328

WANG, W., Cheong, F. (2005). A framework for system dynamic modeling of the mobile commerce market. International Congress on Modeling and Simulation Modsim, 5, 1787-1793.

http://www.juniperresearch.com [Accessed December 12, 2012]

http://www.nfc-research.at/ [Accessed December 12, 2012]

http://www.businessdictionary.com/definition/emergingtechnologies.html [Accessed January 13, 2013]

http://moscatiello.net/Forecasting\%20the\%20Unit\%20 Cost\%20of\%20RFID\%20Tags.pdf). [Accessed January 13, 2013]

http://www.rfidjournal.com/faq/20 [Accessed January 13, 2013]

http://www.nfc-research.at/index.php?id=5 [Accessed September 15, 2013] 